\title{
The Central Mental Hospital, Dundrum-Small can be Interesting
}

\author{
Charles Smith, Medical Director, Central Mental Hospital, Dundrum, Dublin
}

The Central Mental Hospital, Dundrum opened its doors for business in 1850. We cannot be sure why our English masters at the time considered it more urgent to open a security hospital in Ireland before planning and constructing Broadmoor. Were the Irish, as a race, sick and dangerous, or does an old institution like Dundrum reflect the views of the colonists on the colonised!

In 1986 various government officials made authoritative statements predicting the hospital's demise, anticipating closure within a few years.

This review can be likened to the recorded reminiscing of a death row inmate who has to come to terms with the prospect of premature death but who believes in magical reprieve. At this moment of truth it would seem valuable to protest that there is relevance and interest in an institution that looks decidedly dated and to record some of the accumulated wisdom and practices that have evolved here over time.

\section{Transfers from prisons}

Dundrum has 100 beds, 70 of them filled with mostly chronic illness; chronic psychosis and mental handicap, organic brain syndromes and occasional affective illness form the main diagnostic categories. A 1985 article by Sheppard \& Hardiman goes into much more detail. ${ }^{1}$ The 30 remaining beds are decidedly active, accepting approximately 250 prison transfers every year. This group is predominantly personality disordered and it can be escape interested and escape assisted. We have had armed escapes in the hospital in recent years, but that is nothing new. Our hospital archives, enormously interesting and amusing as well, record an armed escape as far back as 1926!

The distress leading to transfer from prison is mostly situational, often linked to self injury or aggressive threats, and it quickly diffuses in a less authoritarian medically influenced hospital setting. We are very good at psychological first aid and the patient-inmate is usually ready for return to the prison battle front after three to four weeks of altered management.

The transfer machinery is very informal, easy to initiate or reverse; it is simply an assessment, rather than a certification of illness, process. Locally it is called "A Hospital Order". The form is signed by "a person authorised in this behalf by the said minister"2 and the transferee is not stigmatised by certified insanity. Since the Forensic Psychiatric Service in turn services the prisons, in most instances the doctor suggesting the transfer at the prison will also be the receiving treating doctor back at the hospital. We recommended this system.

The ready access to a hospital bed undoubtedly reduces the potential for prison suicides and the single doctor involvement makes displacement of responsibility, getting rid of trouble by slipping it out to hospital in an illness guise, much less likely. We transfer readily, we treat quickly, and return, more intact, large numbers of prison inmates.

\section{Patient categories}

We like separation of our patients into two broad groups. The first group is "predominantly ill" and secondarily dangerous and it deserves strenuous treatment responses with less emphasis on accompanying security. With the illness under control dangerousness should recede and ordinary progression towards community care is achievable.

A second broad group is "predominantly dangerous and criminal" and while psychotic illness may be present, and is often paranoid in content, nevertheless the main threat derives from well established abnormal behaviour patterns which are basically anti-social. This group needs surrounding security as a priority when treatment is attempted.

The classical "predominantly ill" diagnosis is either schizophrenia or affective illness and dangerousness is linked to delusions and misinterpretations. The classical "predominantly dangerous and criminal" diagnosis is paranoid psychosis that emerges from a life-long pattern of trouble, often including conduct disorder in childhood, moving onto delinquency in adolescence, and graduating towards adult criminality. One could argue that there is always a second diagnosis present, namely that of personality disorder. This group or some members of it at least might be better treated in a prison psychiatric unit because it does represent a more serious security risk. The first group can be easily handled in a moderately secure hospital.

\section{The hunger strike threat and the dirty protest}

Because of unhappy events in other parts of this country more of this form of protest has crept into our places of detention. The earliest reference to the dirty protest does not come from Northern Ireland jails. Certainly, before it appeared there, it was practised elsewhere. ${ }^{3}$ While it is daunting, nevertheless, it is not life threatening. The hunger strike weapon is essentially more serious and it deserves somewhat more discussion.

The guidelines laid down by the Tokyo Declaration ${ }^{4}$ are enormously useful for the practising doctor confronted with self imposed starvation and clearly when the choice to self starve is made rationally and logically, where it is not part of psychotic illness, then medical intervention is not indicated or even permitted. That means, thankfully, an end to the vulgarity of forced feeding.

This hospital has not had to cope with a rationally 
entered, politically motivated hunger protest, nor should it have to, but because there is contagion in human behaviour we have had several instances of illness related starving and many threats of hunger striking to achieve personal rather than ideological gain. The decision to treat illness is a simple one and anti-psychotics work well if one has time on one's side, particularly when the patient is still taking fluids. If fluids are refused, however, one may have to use ECT as a life saving alternative. For obvious reasons an early psychiatric evaluation makes sense. When illness is diagnosed treatment becomes obligatory. Where illness is excluded "treatment" becomes an assault.

The manipulative striker ends his protest when he is told that there will be no medical intervention. It is as simple as that.

There is a problem in the terminal stages of politically motivated starvation. Obviously organic confusion arises at some point and during it the protestor may be unable to continue expressing his determination to die. Family members may request medical intervention at that stage and the attending doctor has a dilemma if there are no earlier, clearly talked out arrangements and agreements on inactivity. A soon to be published book, already previewed in the Guardian newspaper, dramatically focuses on the dynamics of hunger striking and should make its way on to forensic psychiatry shelves. ${ }^{5}$

\section{Hostages and sieges}

Hostage-taking during or after a completed escape is beginning to worry some security establishments. The psychological stages of hostage taking and keeping are well understood and indeed documented to the point where the organised hostage taker can know as much about the anatomy of kidnapping as those trying to negotiate the hostage's release later. Dundrum has avoided hostage taking, but only just.

We had a close encounter quite recently where a young offender patient escaped to the intermediate freedom of a disused hospital building within the grounds. His original offence had involved taking an infant and its young mother hostage while trying to escape from a police investigation. Dundrum breathed a sigh of relief when he passed our administration block without taking some female hostages during his run towards freedom.

He barricaded himself in securely and we started to react in a confused, disorganised way. We worried that he would set fire to the house, get onto the roof and from there to an adjoining wall. We anticipated the embarrassment of TV cameras focusing on our ineptitude and clumsiness. It was all resolved within a few short hours by good fortune and, I think, our decision to go about ordinary institutional business while trying to sort out the chaos. Delivery vans arrived at the gates and were let through to make a normal drop. He could see this happening. Staff left the location to return to the main building for meal breaks. We played down the drama and the drama played itself out. It is worth remembering as a strategy.

\section{Clinical material}

We have our share of interesting phenomena, including at the present time the fourth brother in a family to pass through our system. Currently we house four matricidal patients, obviously not the four brothers already mentioned. We feel that mothers and other family members can be put at risk if they are asked to participate in detention certification of a paranoid patient. We also quite recently admitted a full blown Koro syndrome in a patient who is decidedly Irish. Our archives bulge with fantastic case recordings, including a Capgras documented in 1889, long before it was recorded as a syndrome and one of the earliest admissions to the hospital had killed all seven of his crew in a ship off the south Irish coast.

It pained us terribly to lose our training approval for the College membership examination following the last visit. Perhaps inferiority breeds content but we did view our training experience as unique and relevant and we had no trouble filling training posts. We are poised confidently to return to favour.

We would very much like our administrative colleagues to consult with us about the future of forensic psychiatry in Ireland. The response of the Irish Division of the College to the local 'Planning for the Future' document has already been published in the Bulletin. ${ }^{6}$ We wonder about the increasing pressures on our service as general psychiatry becomes more community based and as our prisons grow in crisis with overcrowding and inadequacy.

If the closure of Dundrum is seen as possible by someone in the Department of Health it is certainly not obvious to us.

REFERENCES

${ }^{1}$ ShEPpard, N. \& Hardiman, E. (1986) Treatment of the mentally ill offender in Ireland. An examination of the forensic psychiatric services. Irish Journal of Psychiatry, Spring 1986, 13-19.

${ }^{2}$ Section 17 (6) Criminal Justice Administration Act 1914. As adapted.

${ }^{3}$ BoYLE, Jimmy (1977) A Sense of Freedom. Edinburgh: Canongate.

${ }^{4}$ Declaration of Tokyo as adopted by the Twenty Ninth World Medical Assembly (1975) Tokyo, Japan.

SBeresford, DAVID (1987) Ten Men Dead. London: Grafton. (The Guardian, 27, 28, 29 April 1987).

${ }^{6}$ Response of the Irish Division to Planning for the Future (1986) Bulletin of the Royal College of Psychiatrists, 10, 130-138. 